\title{
DESIGN POINT. AN INTEGRATED E-LEARNING \& INDUSTRY 4.0 FASHION PLATFORM FROM ITALY TO ZAMBIA
}

\author{
Dalia Gallico \\ Università San Raffaele, Roma, Italy
}

\begin{abstract}
The project focuses on a standard of sustainability and multiculturalism applied to the fashion industry 4.0. Culture has a major impact on reducing poverty and contributes to a development, which is primarily human, inclusive and fair.

The result of the construction of a cultural and educational bridge, through E-learning platform between Italian design and the artisans of developing countries at each different season, or low income ones, such as Zambia and others in South America, Africa and Asia.

Design Point (the name of the project) goes in the field on mission, and after a first period of meeting and research of the various indigenous skills, many of which are dying out, it studies together with local artisans and contact persons, how to develop a product fashion-textile-accessory combining the host country's traditional craftsmanship with the well known Italian design and savoir-faire on E-learning platform to study and Industry 4.0 skills to create and sell new collections.

A cooperation very functional to bilateral development, that can count on a partner which in this dynamic at the end turns into an instrument: Technology. Acknowledging fashion's potential, as cultural activity, to provide significant opportunities for decent work for men and women around the world. Now it is possible thanks to remote education and work, to recover a research difference gap of decades of years. Nothing about them without them, an exchange of know-how and know-why, whose reactivation generates in the local populations a sense of self sufficiency, deriving from the direct employment creation, business and training related to these recovered competencies and cultural resources. In addition to the inducement, generated by the international promotion of a positive image of the country that attracts investment and triggers tourism therefore commercial interest, compared to remote geographical areas mostly unknown or maybe known for the wrong reasons.

Moreover, to overcome the lack of trade opportunities, the access to the international market is facilitated by a special agreement which allows the sale of ethical products resulting from this project, through one of the world's first e-commerce platform, which ensures a transparent business process management.

This activity has objective to oppose a welfarism that has proved so far to be inefficient. A goal of integrationial contamination, which promotes a cultural crossover, in which no identity is ever negotiated. Not charity, but serious work and cooperation with distance e-learning, the creation of an industry 4.0 fashion laboratory in Lusaka, the sale on e-commerce international platform.

To promote custom-made fabrics, exclusive samples are created by locals and subsequently presented at the international Milan Fashion week, where orders are collected within a quantity compatible with the local production capacity and commissioned to the communities, to finally return to Italy, and be finished manually by Italian seam stresses. An ideal Laboratory of Nations, which permeates the dignity of work, as an indispensable element at any latitude, thanks to ICT. This mission statement is a voluntary declaration, whose uniqueness is revealed as a reflection of the designer's personal multicultural DNA, translated into her signature style, as well as into a business model of sustainable technological development. These missions are officially supported from time to time by the various entities such as: Ministries of Foreign Affairs, Ministry of Culture and Trade, Embassy cooperating with the coordination of the United Nations.

The projects are structured by University San Raffaele Roma in consultation with local authorities and Foundations, so that there is always transparency and unity of purpose in achieving common and shared promotion and development objectives. A new business model and sustainable development on E-learning and Industry 4.0 platform made with collaborative innovation from Italy to Zambia in seven steps:

Craftship recovery; Cultural Heritage as enabler and a driver of sustainable Development; Enhancing opportunities through knowledge transfer and exchanges on E-learning platform; Enterprise creation with Fashion Industry 4.0; Promotion, as Tourism and Commerce developer; Enduring International Trade Development with E-commerce Platform; Integrationist contamination by technology.
\end{abstract}




\section{KEYWORDS}

Collaborative Innovation, Design of Societal Systems - rethinking, Managed Learning Environments (MLEs), Learning Theories and Approaches, E-Learning Models, E-commerce

\section{INTRODUCTION}

Fashion design occupies in present-day reality a role that involves sharp relief - directly or indirectly - a number of areas and types of professions. The project Design Point aims to encourage an increasing development and a greater appreciation of the excellence of the production system in Zambia. This will raise the degree of development / Zambia internationalization of production using the Milan Fashion design education (product, packaging, marketing, management, communication, etc.) as a driver of competitiveness / growth opportunity for exchange of local products with foreign markets is the focal point from which begins the project implementation.

Actually, the proposal, based on expertise gained from the reality of Milan, is just part of the value that design plays in that area and that - if properly developed and promoted to practical applications - is able to generate value for the companies involved. The project in particular promotes the establishment of a "Design Point" in Zambia that could become a platform for exchange and concrete support to the innovation of small/medium Zambia artisans through a strong focus on the value of design and new technology.

\section{DESIGN POINT}

The Design Point is an E-learning and Co-working Area where the designers from zambian companies are facing every day, developing a capacity to interpret and identify potential opportunities still untapped by local system: developing a new product and / or improve an existing business decisions, using the new address / new adaptation of existing materials (new ideas and products, prototypes, etc.) or enhancing the image of their products and presentation / packaging of their products (suitable for creating a brand, develop new packaging, etc.) are some examples and real cases that the design point -along with other measures- face on a daily basis in the interest of local companies. The Centre also designs the task and the role of promoting and building -together with partners- more and more ambitious planning and development paths, capable of enhancing the promotion and the outlet of the companies involved in Zambia, developing a constructive synergy with Milan / Lombardy on E-commerce platform that will increase international appreciation Zambia handicraft offering new opportunities for development and growth.

This program satisfies the general objective of education for university degree in training of human resource of fashion engineering, which partly upgrades people's intellectual level, carries out researches and tech-trans those can create scholars, new products to develop the economy, national defense and security and international integration. The curriculum trains an engineering of good political perspective, morality, knowledge, professional practical skills, researching and practical scientific and technological developing abilities corresponding degrees awarded; bachelors possess good health; originality and professional responsibility, new environment adaptability; awareness of people serving.

Graduates from this program have a scientific education and a complete professionalism which allow them to gain success in engineering career generally, and fashion engineering particularly.

Specific objectives:

- Have fundamental engineering and major knowledge: processing procedures from textile to fashion finishing and technical textile products, production and maintenance systems, abilities in new product design and development which helps to detect and solve problems related to design and manufacture in fashion production systems, to solve technical aspects thanks to knowledge and modern IT tools.

- Have individual skills, professional morality, good conversation and team-work skills enabling to join a multidisciplinary, multi-cultural and international working environment.

- Have knowledge of technical international language, so to improve him-/herself and exchange knowledge with others.

- Have understanding in economy, politics, fundamentals in social sciences, and humanity which are appropriate to usefully contribute to the sustainable development of the society and community. 

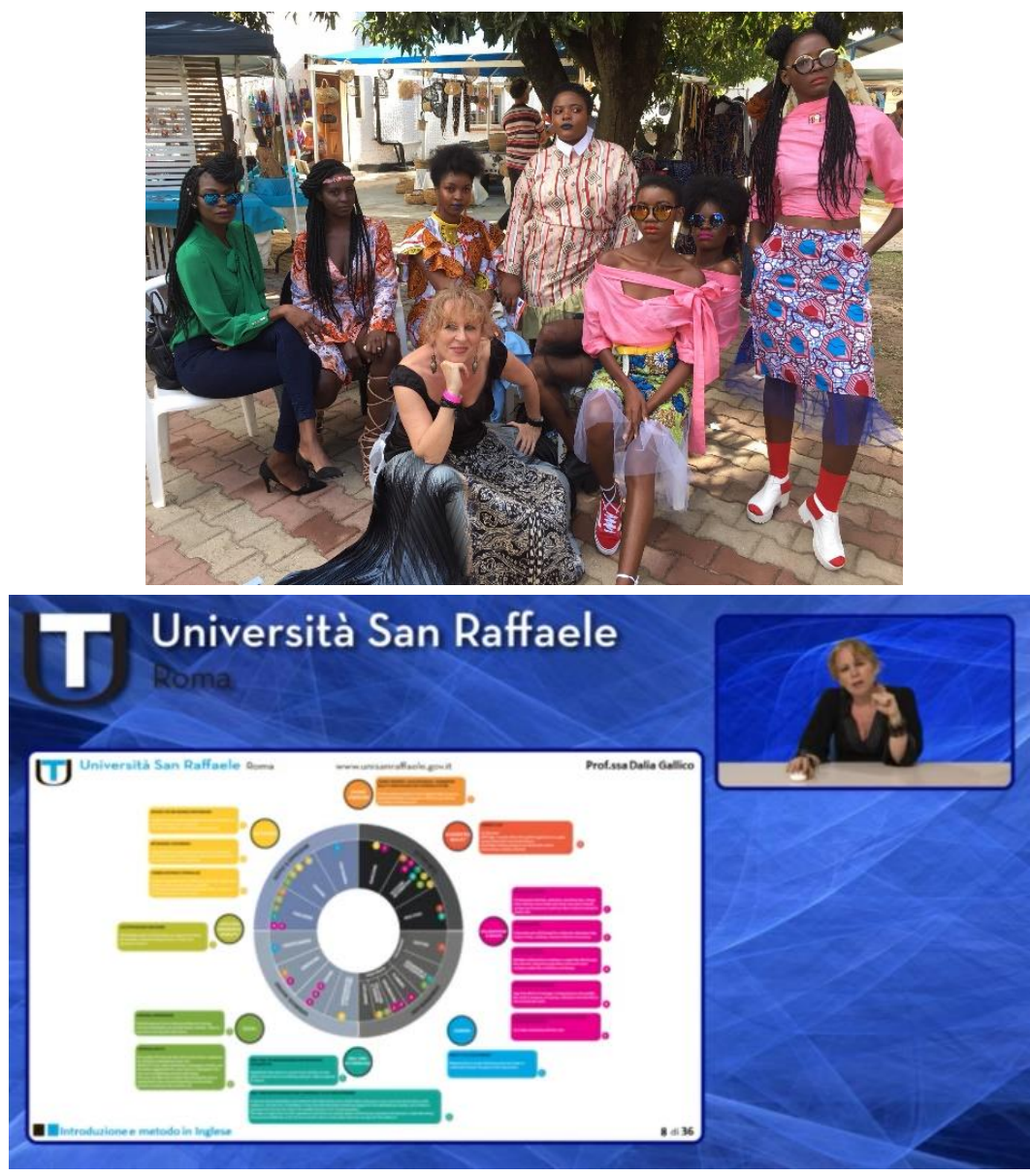

Figures 1. Zambian Designer's meeting with Director at "Design Point" in Lusaka, Zambia with Prof. Dalia Gallico. Screenshots. E-learning Design \& Business lessons

\section{TECHNOLOGICAL APPLICATIONS AND CHARACTERISTICS}

As part of the project devoted to the dissemination of high quality material in Design, University San Raffaele Roma with the portal https://design.uniroma5.it/ is designed to allow easy and flexible access to a big potential user arena. In this sense, the portal is based on some of the most widely used, reliable and functional tools in the field of content management, electronic commerce, and technology training. Inside the portal, the Joomla and VirtueMart platform is integrated in conjunction with Moodle for the sale and use of online courses. The implementation of the online sales system for the https://design.uniroma5.it/ site is concerned with the Moodle, Joomla and VirtueMart platforms. The latter is an add-on for Joomla cms that allows you to extend its capabilities to create and manage an e-commerce portal. This tool, in conjunction with an API implementation, enables the integration of Moodle courses with the sale and purchase auto-subscription.

The basic component of VirtueMart covers the basic features of an on-line shop (online catalog submission, file download, cart), but add-ons that implement additional functionality such as product search or preview in. The shop management allows you to modify the seller and related product information by entering basic information (name, identifier), advanced (weight, unit of measure, size, related products) and images (Picture of the article).

Streaming video with Vimeo provider. To increase the portability of the contributions and to exploit the potential offered by streaming video, it has been chosen to use a professional broadcast service. 


\section{DESIGN POINT: FASHION INDUSTRY 4.0 TO ZAMBIA}

The Fashion Design Point Laboratory set up in Lusaka is unique and available to all designers who need it. A trained instructor is always there available. Design point automates the entire personalization process, from order reception and product development to the final cutting stages. Resulting from a four-year research-and-development process, the digital solution for on-demand production was developed based on Industry 4.0 principles.

The project Design Point allows Zambian designers to produce personalized clothing at the same speed as ready-to-wear and avoid overstocking by producing in precise quantities.

It is available in the form of two packages, one dedicated to made to measure, with pattern adjustments, and the other to customization, with product characteristic alterations. This turnkey solution automates on-demand production right from order reception to production development stages and the cutting room. Companies can define their desired product personalization criteria for each item depending on the package, and launch production processes right from the get-go, without interfering with their standard workflows.

This innovative cloud-based platform solution ensures efficient made-to-measure and customization production processes and facilitates nearshoring for companies that offer individualized products. This technology is up and running and can be used by the fashion industry on a plug-and-play basis.

Born at the confluence of two worlds, fashion and software, Design Point converted iconic Italian luxury brands to computer assisted design (CAD). The software: Kaledo for textile design and creation, Modaris for product development and 3D prototyping, Diamino for marker making, Kubix Link and Fashion PLM for collaborative management of collection life cycles.

Equipment in automated cutting, cutting room equipment too. The solutions - integrated machines and software - are adapted to each market, as well as to the broad diversity of materials processed: fabrics, leather, and textiles. All the cutting solutions are compatible with Industry 4.0 principles.

Design Point Services are deployed in three areas: support, training and consulting. Support and preventive and predictive maintenance services assist our customers remotely and on-site, ensure the availability of cutting equipment and make the latest versions of our software available. Training provides a continuous transfer of skills to empower the users of solutions throughout their customer journey. Finally, consulting services enable to fully benefit from o solutions and to take an optimization approach.

We cross-reference and analyze it to better understand the processes and to propose new services and applications, such as driving our customers' performance based on their own objectives or the best indicators from their sector.
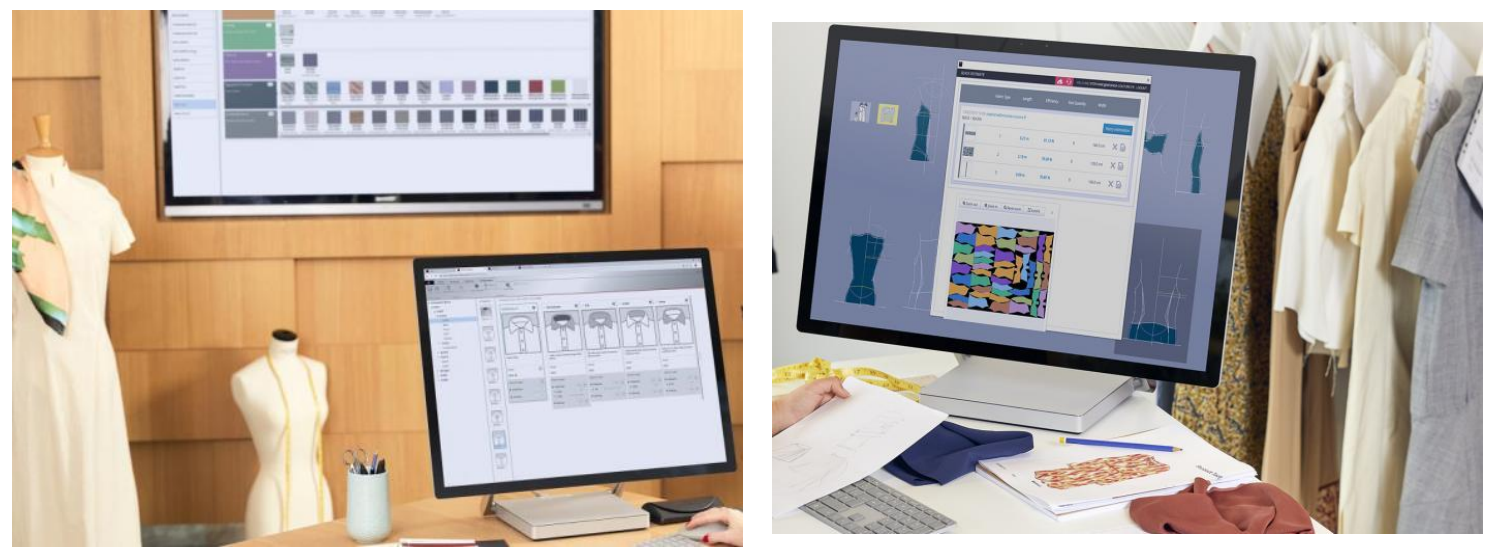

Figures 2. Design Point Cad instruments for Fashion

\section{CONCLUSION}

Fashion design as a cross-operative clot? An industrial design not only as a product but also as communication and as an image? A focus on product innovation as a complex reality built by the continuous transfer of the outcomes and results? These are the objectives that the Design Point aims to achieve with the leadership of Director Dalia Gallico and the Steering Committee. 
Design point aims to strengthen, deepen, expand, promote and help implement the appropriate conditions for the enhancement of design, with technology support, from the territory of Milan, Italy to the world.

Its purpose is to promote and help implementing the appropriate conditions for the design of goods and services, through the cultural debate, the intervention in the institutions, the provision of services and technology. It is involved in the design of products, services, visual communication, packaging, interior architecture, and environmental design.

Design Point is exploitation of research and industrial skills and excellences. Skills development involves, among the others, the next fields:

- Advanced communication media, based on Web 2.0 technologies, suitable to support B2C sale for fashion design, jewellery and trinkets.

- Analytical instruments able to produce channels analysis and customer segmentation in automatic way;

- Logistic organizational models with high performance driven to offer a worldwide service at top level, also flexible and affordable.

New technologies allow to create global communities with a lot of users sharing contents. This proves that management technologies can do more and more. The project aims to use these technologies for the marketplace development to build an international community on the Italian design know.

Related to growth of ICT technologies, the project allows the development and joining of innovative technologies Web 2.0, able to:

1. Create a place where all designers are connected, both Italian and Zambian, could develop ideas, contents, events, opinions, all related to fashion design. Advanced technologies Web 2.0 join potential of companies, designers, students, interested people and keen on fashion design.

2. Translate the characteristics of products in a way that a user/buyer can exactly understand and feel the additional value of the product just through the web (experience on E-commerce platform).

3. Use buyer's profile and location data to increase the offer and create return information flows which could be translated into marketing information available for vendors;

4. Create data exchange with the industry 4.0 platform able to assure the quality of logistic performance expected from the market

The key factors for this are the increased implementation of the Internet of Things (IoT) and the digitalization of the industry. As products are usually at the heart of manufacturing business, data and analytics are often aimed at refining product development rather than the end-to-end production process. Due to constantly increasing expenses, companies in the sector are always looking to:

- $\quad$ Reduce the cost of manufacturing

- Increase production efficiency

- Minimize waste, optimize the use of energy and other resources

The final product is unique, and knowledge, concepts and system support developed can be used later in other contexts to support innovation trough design. At least the Design Point's model is in line with 6 of the 17 United Nations Sustainable Development Goals (SDGs): No Poverty, Gender Equality, Decent Work and Economic Growth, Reducing Inequality, Responsible consumption and production Partnerships for the Goals.

\section{REFERENCES}

Bentley, T. (1998). Learning beyond the classroom: Education for a changing world. London: Routledge.

D’Andrea A., Ferri F., Fortunati De Luca L., Guzzo T (2009). "Mobile Devices to support advanced forms of e-Learning" Handbook of Research on Multimodal Human Computer Interaction and Pervasive Services: Evolutionary Techniques for Improving Accessibility. Editor: Patrizia Grifoni, IGI Global

Dillenbourg, P., Baker, M., Blaye, A., \& O'Malley, C. (1996). The evolution of research on collaborative learning. In E. Spada \& P. Reiman (Eds.), Learning in humans and machine: Towards an interdisciplinary learning science. Oxford, UK:

Gallico D (2013). Contam-Innovation Cinquecento icone tra design, cultura e innovazione. Bologna:Logo Fausto Lupetti editore

Gallico D, (2016). Rapporto nazionale sul Design nelle imprese italiane (dalla A alla Z) isbn 9788868741518 Logo Fausto Lupetti editore

Gallico D, (2020). Moda in Formazione Bologna:Logo Fausto Lupetti editore Isbn 9788868742072

Grew, P., \& Pagani, E. (2005). Towards a wireless architecture for mobile ubiquitous e-learning. Workshop on Learning Communities in the Era of Ubiquitous Computing, Milan, Italy. 